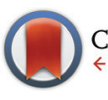

CrossMark

$\leftarrow$ click for updates

Cite this: Food Funct., 2015, 6, 714

Received 5th December 2014,

Accepted 20th January 2015

DOI: $10.1039 / \mathrm{c} 4$ fo01119h

www.rsc.org/foodfunction

\section{Food derived microRNAs}

\author{
Anika E. Wagner, ${ }^{*}$ Stefanie Piegholdt, Martin Ferraro, Kathrin Pallauf and \\ Gerald Rimbach
}

\begin{abstract}
Foods provide fats, carbohydrates, and proteins as well as vitamins, minerals and trace elements. These dietary factors may influence cellular processes by regulating endogenous microRNA expression. MicroRNAs are non-coding regulatory molecules which affect gene expression the post transcriptional level. It has been shown that plant and animal derived foods also contain microRNA. Yet, it is unclear if and to what extent plant and animal food derived microRNAs are absorbed by mammals. Thus, future studies need to better address absorption, tissue distribution and function of dietary plant and animal derived microRNAs in the context of human health and disease.
\end{abstract}

Over the last decade it has become apparent that nutrition does not only provide fats, carbohydrates, proteins, vitamins, minerals and trace elements. Beside macro- and micronutrients, plant and animal derived foods also contain considerable amounts of so-called microRNAs.

MicroRNAs are evolutionarily conserved small non-coding RNAs consisting of on average 22 nucleotides..$^{1-5}$ They mediate post-transcriptional changes in gene expression usually through binding to the $3^{\prime}$ untranslated region (3'UTR) of target mRNAs with their seed region (nucleotides 2-7). Depending on the base pair complementarity between the microRNA and the target mRNA, the target mRNA is either degraded (perfect match) or the ribosomal translation is blocked (imperfect binding) which in turn influences the cellular phenotype (for microRNA processing see Fig. 1).

It has become increasingly evident that microRNAs are involved in the regulation of a large number of cellular processes. ${ }^{6}$ MicroRNAs are found in all human cells and currently almost 2000 sequences are listed in the microRNA database http://www.mirbase.org. Other important microRNA databases include http://www.microRNA.org, http://www.ncrna.org and http://www.mirdb.org. It has been hypothesized that as many as $60 \%$ of the human protein-coding genes may contain microRNA binding sites. ${ }^{7}$ In line with this estimation, microRNAs play a role in the genesis of obesity, diabetes, neurodegenerative diseases and cancer. ${ }^{8,9}$ Consistently, microRNAs were shown to influence insulin production in pancreatic $\beta$-cells by regulating transcriptional repressors, ${ }^{10}$ miR-33 and other microRNAs were shown to affect lipid metabolism, ${ }^{11}$ miR-15

Institute of Human Nutrition and Food Science, Christian-Albrechts-University, Hermann-Rodewald-Str. 6, 24118 Kiel, Germany.

E-mail: wagner@molecularnutrition.uni-kiel.de; Fax: +49 431880 2628;

Tel: +494318805313 and miR-16 promote apoptosis through inhibiting the expression of pro-apoptotic Bcl-2 ${ }^{12}$ and miR-376b and miR-30a regulate autophagy by targeting pro-autophagic beclin $1 .^{13,14}$ Given these implications for health and disease, interest in developing microRNAs as therapeutics for illnesses is rising and a first liposome-based microRNA mimic (MRX34) has reached phase I clinical trials. ${ }^{15}$

Diet may also influence cellular processes by regulating microRNA expression ${ }^{16}$ (Fig. 2). Food components such as vitamins (e.g. vitamin $\mathrm{D}$, vitamin $\mathrm{E}$, folate) and secondary plant metabolites (e.g. epigallocatechingallate, curcumin, resveratrol, quercetin, isothiocyanates) were reported as modulators of microRNA levels. ${ }^{6,17-19}$ Moreover, there has been a report that microRNAs from food may regulate gene expression in mammals. It was shown that miR-168a from rice is transported from the gastrointestinal tract to target organs in mice. In murine liver, this plant-derived microRNA bound to lowdensity lipoprotein receptor adapter protein 1 (LDLRAP1) mRNA and inhibited LDLRAP1 expression, thereby interfering with cholesterol transport. ${ }^{20}$ Another recent study published by the same group suggests that in influenza-infected mice honeysuckle exhibits its anti-viral potency via microRNA-2911. ${ }^{21}$ Yet, a so-called cross-kingdom regulation by microRNAs is still under debate ${ }^{22-24}$ since a different group of researchers could not detect plant microRNAs after feeding in mice $^{25}$ and studies in humans did not lead to detectable amounts of microRNAs in the plasma after consumption of fruits ${ }^{26}$ and broccoli sprouts. ${ }^{27}$ In contrast, Lukasik and Zielenkiewicz ${ }^{28}$ identified plant-derived microRNAs in exosomes of human and porcine breast milk and, by using a bioinformatics approach, predicted their potential human target mRNAs. Interestingly, Melnik and co-workers ${ }^{29}$ relate the atopy-preventing effect of raw cow milk to exosomal miR-155 which is present in high amounts in raw cow milk (especially 


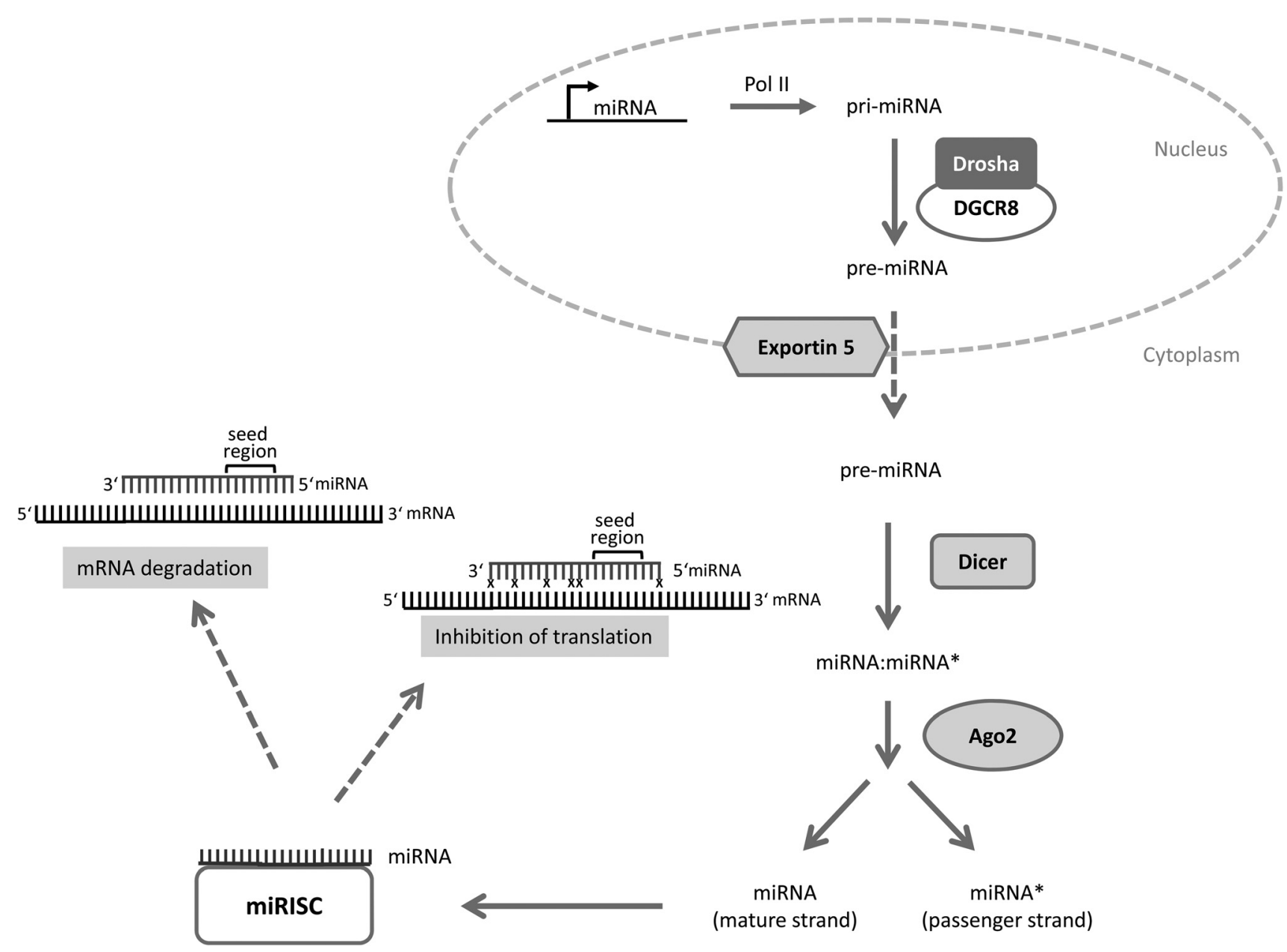

Fig. 1 microRNA processing. Primary microRNAs (pri-miRNAs) are specifically transcribed from microRNA genes by polymerase II (Pol II). PrimicroRNA is cleaved by an enzyme complex consisting of Drosha and DGCR8 (DiGeorge critical region 8) into a precursor microRNA (pre-miRNA) of $\sim 70$ nucleotides which is exported from the nucleus into the cytoplasm by the nuclear export protein exportin 5 . Once in the cytoplasm the premiRNA is processed by the enzyme Dicer into a miRNA : miRNA* duplex which is then unwound by Ago2 into two single strands. Ago2 is part of the miR-RISC (microRNA - RNA induced silencing complex; miR-RISC). The miRNA strand is the mature strand whereas miRNA* represents the passenger strand which is usually degraded. However, some passenger strands enter the RISC and function as a "normal" microRNA. The mature miRNAstrand connects to the RISC and finally targets the mRNAs. Depending on the complementarity between mRNA and microRNA either the translation is inhibited or the mRNA is degraded. $x$ indicates mismatch between microRNA and mRNA (modified according to ref. 4).

colostrum) and also in human breast milk. miR-155 is known to play a pivotal role in the development of the immune system and especially in the activity of regulatory $\mathrm{T}$ cells (Treg). ${ }^{29-31}$ While naked microRNAs are highly unstable and are quickly degraded by omnipresent RNases several papers note that circulating microRNAs in blood and various body fluids are highly stable which predisposes them as a potential biomarker for malignant and non-malignant diseases. This exceptionally high stability is owed to the fact that microRNAs can either form complexes with proteins or be packed into small vesicles originating from endosomal membrane compartments or the plasma membrane itself. ${ }^{32} \mathrm{~A}$ high number of microRNAs in human breast milk are present in microvesicles or exosomes which protect them from rapid degradation by RNases. ${ }^{33,34}$ It has been proposed that microRNAs are involved in cell-cell communication and play an important role in the immune system maturation of the infant. ${ }^{33,34}$ There is evidence that exosomes are transported by human cells through phagocytosis and carrier-mediated processes. It was shown that cow-milk-derived exosomes are transported by human intestinal cells following a saturated kinetic process which can be inhibited at low temperatures as well as through an elimination of exosome surface proteins. ${ }^{35}$

Recently Zempleni and co-workers have demonstrated that humans seem to absorb cow milk derived microRNAs in significant concentrations and that these microRNAs seem to affect gene expression in human white blood cells, cultured kidney cells, and mouse liver. In fact, post prandial pharmacokinetic analyses suggested that miR-29b and miR-200c were absorbed in humans and, most importantly, the expression of RUNX2 (runt-related transcription factor 2), a target of miR-29b, was modulated after milk consumption indicating that microRNAs in milk may be considered as bioactive food compounds regulating gene expression and signal 


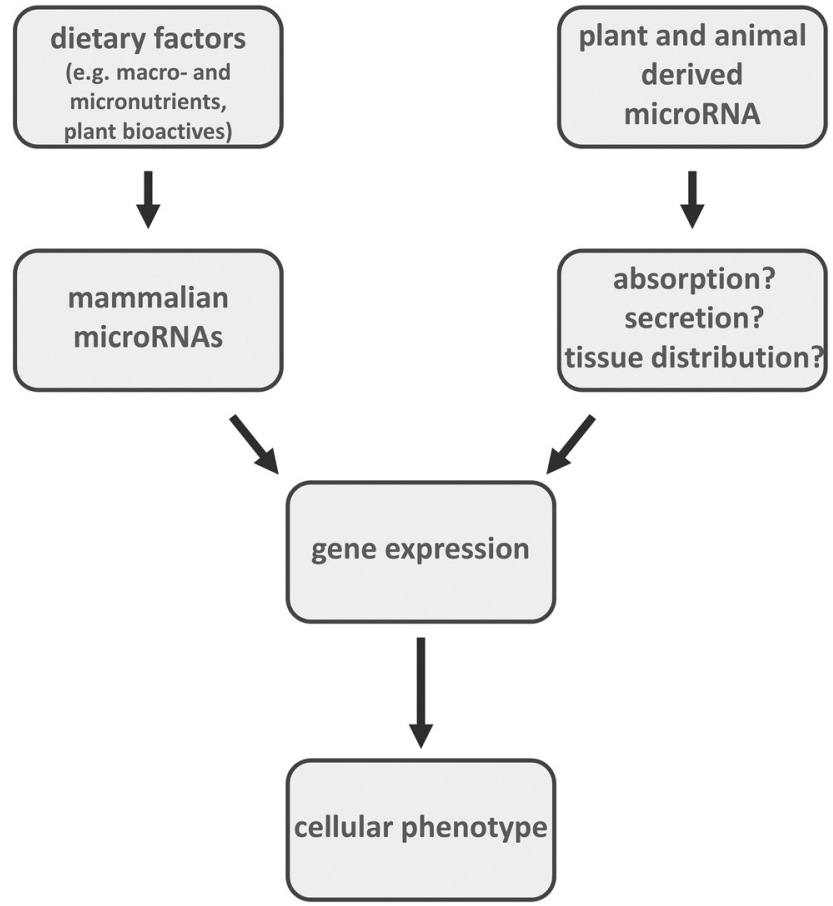

Fig. 2 Dietary factors (e.g., macronutrients, minerals, trace elements, vitamins, plant bioactives) have been demonstrated to target mammalian microRNA. In addition, following absorption, secretion and tissue distribution, plant (e.g., rice) and animal (e.g., cow milk) derived microRNAs have been suggested to affect gene expression, thereby modulating cellular phenotypes.

transduction in humans. Interestingly, the authors could also show that endogenous microRNA-synthesis cannot compensate for the milk-derived microRNAs in mice fed a microRNA depleted diet. ${ }^{27}$

Based on dietary surveys of European consumers, we conducted a literature search into the microRNA composition of commonly consumed food such as milk, meat, cereals and oil plants like rape. We searched Pubmed for studies up to 2014 and included 15 foods in our final analysis and if data were available we filtered the results for the 15 most abundant miRNAs present in the corresponding food items (Table 1).

Sophisticated tools (e.g. microRNA.org) allow the identification of corresponding mRNA targets of these food-derived microRNAs. It may be possible to predict the regulatory function of foods on the basis of their microRNA composition. However, it has to be taken into account that one microRNA normally targets several mRNAs and one mRNA can be targeted by several microRNAs. In addition it has to be considered that the biological activity of microRNAs does not necessarily correlate with their abundance but rather with their presence in exosomes. However before comprehensive food microRNA data bases are released, it needs to be assured if and to what extent microRNAs are absorbed in the gastrointestinal tract. Moreover, the mechanisms of intestinal absorption, bioavailability, tissue distribution and function of exogenous microRNAs should be established.

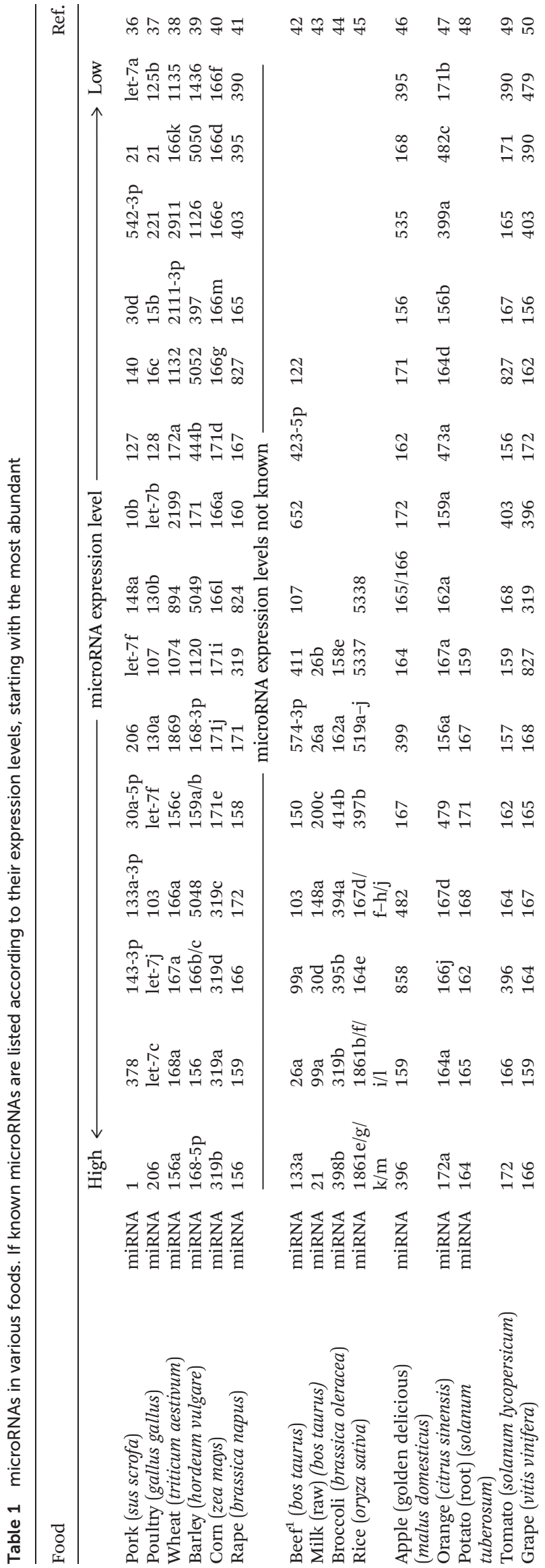




\section{Conflict of interest}

Anika E. Wagner, Stefanie Piegholdt, Martin Ferraro, Kathrin Pallauf and Gerald Rimbach declare that they have no conflict of interest.

\section{References}

1 G. Egger, G. Liang, A. Aparicio and P. A. Jones, Nature, 2004, 429, 457-463.

2 J. Winter, S. Jung, S. Keller, R. I. Gregory and S. Diederichs, Nat. Cell Biol., 2009, 11, 228-234.

3 C. B. Yoo and P. A. Jones, Nat. Rev. Drug Discovery, 2006, 5, 37-50.

4 M. A. Parasramka, E. Ho, D. E. Williams and R. H. Dashwood, Mol. Carcinog., 2012, 51, 213-230.

5 S. I. Ivashuta, J. S. Petrick, S. E. Heisel, Y. Zhang, L. Guo, T. L. Reynolds, J. F. Rice, E. Allen and J. K. Roberts, Food Chem. Toxicol., 2009, 47, 353-360.

6 S. A. Ross and C. D. Davis, Adv. Nutr., 2011, 2, 472-485.

7 D. Sayed and M. Abdellatif, Physiol. Rev., 2011, 91, 827-887.

8 S. Maciotta, M. Meregalli and Y. Torrente, Front Cell Neurosci., 2013, 7, 265.

9 A. S. Ali, S. Ali, A. Ahmad, B. Bao, P. A. Philip and F. H. Sarkar, Obes. Rev., 2011, 12, 1050-1062.

10 T. Melkman-Zehavi, R. Oren, S. Kredo-Russo, T. Shapira, A. D. Mandelbaum, N. Rivkin, T. Nir, K. A. Lennox, M. A. Behlke, Y. Dor and E. Hornstein, EMBO J., 2011, 30, 835-845.

11 C. Fernandez-Hernando, Y. Suarez, K. J. Rayner and K. J. Moore, Curr. Opin. Lipidol., 2011, 22, 86-92.

12 A. Cimmino, G. A. Calin, M. Fabbri, M. V. Iorio, M. Ferracin, M. Shimizu, S. E. Wojcik, R. I. Aqeilan, S. Zupo, M. Dono, L. Rassenti, H. Alder, S. Volinia, C. G. Liu, T. J. Kipps, M. Negrini and C. M. Croce, Proc. Natl. Acad. Sci. U. S. A., 2005, 102, 13944-13949.

13 G. Korkmaz, C. le Sage, K. A. Tekirdag, R. Agami and D. Gozuacik, Autophagy, 2012, 8, 165-176.

14 H. Zhu, H. Wu, X. Liu, B. Li, Y. Chen, X. Ren, C. G. Liu and J. M. Yang, Autophagy, 2009, 5, 816-823.

15 A. Bouchie, Nat. Biotechnol., 2013, 31, 577.

16 L. Garcia-Segura, M. Perez-Andrade and J. Miranda-Rios, J. Nutrigenet Nutrigenomics, 2013, 6, 16-31.

17 C. Boesch-Saadatmandi, A. Loboda, A. E. Wagner, A. Stachurska, A. Jozkowicz, J. Dulak, F. Doring, S. Wolffram and G. Rimbach, J. Nutr. Biochem., 2011, 22, 293-299.

18 A. E. Wagner, C. Boesch-Saadatmandi, J. Dose, G. Schultheiss and G. Rimbach, J. Cell Mol. Med., 2012, 16, 836-843.

19 S. Gaedicke, X. Zhang, C. Schmelzer, Y. Lou, F. Doering, J. Frank and G. Rimbach, FEBS Lett., 2008, 582, 3542-3546.

20 L. Zhang, D. Hou, X. Chen, D. Li, L. Zhu, Y. Zhang, J. Li, Z. Bian, X. Liang, X. Cai, Y. Yin, C. Wang, T. Zhang, D. Zhu, D. Zhang, J. Xu, Q. Chen, Y. Ba, J. Liu, Q. Wang, J. Chen,
J. Wang, M. Wang, Q. Zhang, J. Zhang, K. Zen and C. Y. Zhang, Cell Res., 2012, 22, 107-126.

21 Z. Zhou, X. Li, J. Liu, L. Dong, Q. Chen, J. Liu, H. Kong, Q. Zhang, X. Qi, D. Hou, L. Zhang, G. Zhang, Y. Liu, Y. Zhang, J. Li, J. Wang, X. Chen, H. Wang, J. Zhang, H. Chen, K. Zen and C. Y. Zhang, Cell Res., 2015, 25, 39-49.

22 K. W. Witwer, J. Nutr., 2014, 144, 1880-1881.

23 Y. Zhang, B. E. Wiggins, C. Lawrence, J. Petrick, S. Ivashuta and G. Heck, BMC Genomics, 2012, 13, 381.

24 K. M. Howard et al., J. Agric. Food Chem., 2015, 63, 588592.

25 B. Dickinson, Y. Zhang, J. S. Petrick, G. Heck, S. Ivashuta and W. S. Marshall, Nat. Biotechnol., 2013, 31, 965-967.

26 J. W. Snow, A. E. Hale, S. K. Isaacs, A. L. Baggish and S. Y. Chan, RNA Biol., 2013, 10, 1107-1116.

27 S. R. Baier, C. Nguyen, F. Xie, J. R. Wood and J. Zempleni, J. Nutr., 2014, 144, 1495-1500.

28 A. Lukasik and P. Zielenkiewicz, PLoS One, 2014, 9, e99963.

29 B. C. Melnik, S. M. John and G. Schmitz, J. Transl. Med., 2014, 12, 43.

30 K. D. Taganov, M. P. Boldin, K. J. Chang and D. Baltimore, Proc. Natl. Acad. Sci. U. S. A., 2006, 103, 12481-12486.

31 R. M. O’Connell, K. D. Taganov, M. P. Boldin, G. Cheng and D. Baltimore, Proc. Natl. Acad. Sci. U. S. A., 2007, 104, 1604-1609.

32 S. Grasedieck, A. Sorrentino, C. Langer, C. Buske, H. Dohner, D. Mertens and F. Kuchenbauer, Blood, 2013, 121, 4977-4984.

33 Q. Zhou, M. Li, X. Wang, Q. Li, T. Wang, Q. Zhu, X. Zhou, X. Wang, X. Gao and X. Li, Int. J. Biol. Sci., 2012, 8, 118123.

34 N. Kosaka, H. Izumi, K. Sekine and T. Ochiya, Silence, 2010, 1, 7.

35 S. R. Baier, F. Xie and J. Zempleni, J. Nutr., 2014, 144, 1882.

36 L. Qin, Y. Chen, X. Liu, S. Ye, K. Yu, Z. Huang, J. Yu, X. Zhou, H. Chen and D. Mo, PLoS One, 2013, 8, e72418.

37 T. Li, R. Wu, Y. Zhang and D. Zhu, BMC Genomics, 2011, $12,186$.

38 F. Meng, H. Liu, K. Wang, L. Liu, S. Wang, Y. Zhao, J. Yin and Y. Li, BMC Plant Biol., 2013, 13, 140.

39 M. Hackenberg, P. J. Huang, C. Y. Huang, B. J. Shi, P. Gustafson and P. Langridge, DNA Res., 2013, 20, 109125.

40 M. Kang, Q. Zhao, D. Zhu and J. Yu, BMC Genomics, 2012, 13, 360 .

41 D. Huang, C. Koh, J. A. Feurtado, E. W. Tsang and A. J. Cutler, BMC Genomics, 2013, 14, 140.

42 W. Jin, J. R. Grant, P. Stothard, S. S. Moore and L. L. Guan, BMC Mol. Biol., 2009, 10, 90.

43 X. Chen, C. Gao, H. Li, L. Huang, Q. Sun, Y. Dong, C. Tian, S. Gao, H. Dong, D. Guan, X. Hu, S. Zhao, L. Li, L. Zhu, Q. Yan, J. Zhang, K. Zen and C. Y. Zhang, Cell Res., 2010, 20, 1128-1137.

44 J. Wang, X. Yang, H. Xu, X. Chi, M. Zhang and X. Hou, Gene, 2012, 505, 300-308. 
45 T. Peng, Q. Lv, J. Zhang, J. Li, Y. Du and Q. Zhao, J. Exp. Bot., 2011, 62, 4943-4954.

46 R. Xia, H. Zhu, Y. Q. An, E. P. Beers and Z. Liu, Genome Biol., 2012, 13, R47.

47 Q. Xu, Y. Liu, A. Zhu, X. Wu, J. Ye, K. Yu, W. Guo and X. Deng, BMC Genomics, 2010, 11, 246.
48 W. Yang, X. Liu, J. Zhang, J. Feng, C. Li and J. Chen, Mol. Biol. Rep., 2010, 37, 3081-3087.

49 J. Zuo, B. Zhu, D. Fu, Y. Zhu, Y. Ma, L. Chi, Z. Ju, Y. Wang, B. Zhai and Y. Luo, BMC Genomics, 2012, 13, 7.

50 V. Pantaleo, G. Szittya, S. Moxon, L. Miozzi, V. Moulton, T. Dalmay and J. Burgyan, Plant J., 2010, 62, 960-976. 